\title{
Pathogenicity of Pythium Populations from Corn-Soybean Rotation Fields
}

\author{
B. Q. Zhang and X. B. Yang, Department of Plant Pathology, Iowa State University, Ames 50011
}

\begin{abstract}
Zhang, B. Q., and Yang, X. B. 2000. Pathogenicity of Pythium populations from corn-soybean rotation fields. Plant Dis. 84:94-99.

Corn and soybean have been rotated for decades in the north central regions of the United States, but it is unknown how the use of long-term rotation affects the population of soilborne fungi pathogenic to both crops. Pythium populations were obtained from 73 commercial cornsoybean rotation fields in Iowa from 1993 to 1995. A total of 163 Pythium isolates were obtained from soil, diseased soybean seedlings, or diseased corn seedlings, and these isolates were pooled into six populations according to the source of samples. The isolates were evaluated for their aggressiveness on corn and soybean for each population. Regardless of the source of sampling, each population had many Pythium isolates that were highly aggressive on both crops. Seventy-one percent of the isolates from soil were pathogenic, and $29 \%$ were highly aggressive on both crops. Three populations of Pythium isolates were obtained from diseased soybean seedlings. Eighty-five percent of those isolates were pathogenic, and 49 to $64 \%$ were highly aggressive on corn and soybean. Of the isolates obtained from diseased corn seedlings, $87 \%$ were pathogenic and $43 \%$ were highly aggressive on corn and soybean. For each Pythium population, aggressiveness on soybean and corn (measured by disease index) were highly correlated. Further, 23 P. ultimum isolates were identified from diseased soybean seedlings and tested for pathogenicity on corn and soybean. Disease index of the isolates varied, but the correlation between disease indices on the two crops was significant $(r=0.75, P<0.001)$. The study suggests that long-term corn-soybean rotation fields contain many Pythium isolates that are highly aggressive on seedlings of both crops.
\end{abstract}

Additional keywords: Pythium rot, seedling diseases

Diseases caused by Pythium spp. are common on corn and soybean $(2,11,12$, 14,21,23). Pythium spp. are the most important fungi associated with poor stands when corn (Zea mays) and soybean (Glycine max) are planted in cold soils $(12,14,21,25)$. Several species of Pythium are pathogenic to corn (2) and soybean $(1,24)$, and cause damping-off diseases of both crops. The damage caused by Pythium spp. can result in severe economic losses to corn and soybean growers in the north central region of the United States, where seedling diseases were ranked third in 1991 as a cause of soybean yield losses (3).

Crop rotation has been reported to suppress Pythium populations and reduce diseases on many hosts $(18,22)$. For example, the population density of $P$. ultimum varied among plots with all possible two-crop sequences of soybean, corn, wheat, alfalfa, and oats (22). Rotation of corn with other crops affected the frequency of recovery of isolates pathogenic on corn among populations of Pythium spp. in corn fields (12). Rotational crops vary in their suitability as

Corresponding author: X. B. Yang

E-mail: xbyang@iastate.edu

Accepted for publication 22 October 1999.

Publication no. D-1999-1119-01R

(C) 2000 The American Phytopathological Society hosts, removal of different amounts of moisture and nutrients from the soil, ability to provide various kinds of shading, and production of different exudates and/or residues (8). Thus, crop rotation may influence the presence, density, and development of diseases caused by Pythium $(12,18,22)$.

In the north central region, corn-soybean rotations have been widely used for decades. Previous studies have shown that certain Pythium species may be pathogenic to corn $(2,10)$ and soybean $(6,7)$. However, these studies were conducted on either corn or soybean alone using different isolates $(6,7,10,25)$, not on both crops simultaneously with the same isolates. Variation in aggressiveness within Pythium species has been observed on corn (12) and on soybean (1), but the relationship between the pathogenicity on corn and the pathogenicity on soybean is unknown. To our knowledge, no experiments have been conducted to test whether a single Pythium isolate, regardless of its original host, can cause disease on both crops. Pathogenicity of isolates of $P$. myriotylum and $P$. aphanidermatum was tested on 12 crops, including corn and soybean (16), but pathogenicity of individual isolates on both corn and soybean was not reported. No experimental evidence has shown that a Pythium isolate that is pathogenic to soybean can also infect corn with a similar level of aggressiveness. In addition, no quantitative information is avail- able on the aggressiveness of Pythium species obtained from corn-soybean rotation fields, and it is unknown how the use of a long-term corn-soybean rotation affects Pythium populations. In corn-soybean rotation, it is unclear if a high population density of Pythium that results in soybean damping-off will pose the same risk to the following corn crop when environmental conditions are favorable. This paper reports a 3-year study on the pathogenicity and aggressiveness of Pythium populations obtained from corn-soybean rotation fields.

\section{MATERIALS AND METHODS}

Isolation from soil. Four long-term corn-soybean rotation fields with a known history of seedling diseases were chosen for this study. In the spring of 1994, soil cores $2 \mathrm{~cm}$ in diameter and 3 to $10 \mathrm{~cm}$ deep were taken at each of 15 sites in a "W" pattern in each field. The 15 samples per field were bulked and transferred to the laboratory in ice-coolers. In the laboratory, soil was sieved through hardware cloth with 4-mm openings and air-dried at room temperature $\left(22\right.$ to $25^{\circ} \mathrm{C}$ ) for 24 to $48 \mathrm{~h}$. Techniques described by Martin (15) and Tsao and Ocana (26) were used for $P y$ thium isolation. From each bulked soil sample, $5 \mathrm{~g}$ of soil was suspended in $30 \mathrm{ml}$ of sterilized water. One $\mathrm{ml}$ of this soil suspension was further diluted in $10 \mathrm{ml}$ of sterilized water before a 1-ml suspension was spread on $\mathrm{P}_{10} \mathrm{VP}$ medium (26) in a 9$\mathrm{cm}$-diameter plastic petri dish. Three replicate subsamples were plated from each bulked soil sample. After the plates were incubated at room temperature (22 to $25^{\circ} \mathrm{C}$ ) for 3 days, Pythium colonies were identified and transferred to $2 \%$ water agar (WA) and incubated at room temperature (22 to $25^{\circ} \mathrm{C}$ ) for $24 \mathrm{~h}$ before hyphal-tipping. Six hyphal-tip cultures from each field were chosen arbitrarily, and all isolates were pooled into one population (population 1 in Table 1) for further studies.

Isolation from diseased plants. From 1993 to 1995,73 corn-soybean rotation fields were sampled in 21 Iowa counties. Five to 10 seedlings showing symptoms of damping-off were collected from each field before the soybean growth stage of V3 (4) or the corn growth stage of V2 (13). Diseased seedlings from each field were placed in a plastic bag in ice-coolers and taken to the laboratory for isolation.

To isolate Pythium, the seedlings were washed with running tap water for $30 \mathrm{~min}$. One or two pieces of tissue (3 to $5 \mathrm{~mm}$ 
long) from the edge of a lesion were cut and sterilized for $1 \mathrm{~min}$ in $1 \%$ sodium hypochlorite solution. The surface-sterilized tissues were placed on $\mathrm{P}_{10} \mathrm{VP}$ selective medium (26) (two pieces per plate) and incubated at room temperature (22 to $25^{\circ} \mathrm{C}$ ) for 2 to 3 days in the dark. Pythium colonies were transferred to $2 \%$ WA and incubated at room temperature (22 to $25^{\circ} \mathrm{C}$ ) for 24 to $48 \mathrm{~h}$. Hyphal tips of one to three transferred isolates per field were then randomly chosen, cut under a dissecting microscope, and placed one isolate per plate for further use. Isolates of each year and each crop were pooled into four individual populations (populations 2 to 5 in Table 1).

Identification of Pythium spp. Isolates were identified for Pythium based on the morphological characteristics of sporangia, antheridia, and oogonia of the genus. Isolates of $P$. ultimum obtained from diseased soybean seedlings were identified using the key developed by Plaats-Niterink (27), and 23 P. ultimum isolates were pooled to form a population (population 6) for aggressiveness analysis.

Pathogenicity and aggressiveness tests. Six populations were tested for pathogenicity and aggressiveness of $P y$ thium isolates on corn and soybean. Years, numbers of isolates, numbers of fields, and sources of isolates of each population are summarized in Table 1. A petri dish test method was used to determine the aggressiveness in populations 1 and 2, and a pot test in which seeds were planted in infested soil was used in populations 3,4 , and 5 . Each population was tested one or two times for pathogenicity and aggressiveness on corn and soybean. Hybrid maize 5601 produced by Sieben Hybrids Inc., or P3417 produced by Pioneer Hi-bred International, Inc. in Johnston, Iowa, both susceptible to Pythium, were used. For tests of pathogenicity on soybean, cultivars IA2007 or Kenwood, both developed by Iowa State University, were used.

Petri dish test. Pythium isolates were transferred to $1 \% \mathrm{WA}$ and incubated at room temperature $\left(22\right.$ to $25^{\circ} \mathrm{C}$ ) for 7 days before inoculation. Soybean or corn seeds were surface-sterilized in $1 \%$ sodium hypochlorite solution for $3 \mathrm{~min}$, washed with running tap water for $5 \mathrm{~min}$, and 10 seeds per plate were placed on the Pythium cultures. Seeds also were placed on WA plates as uninoculated controls. The plates were incubated at $10^{\circ} \mathrm{C}$ in the dark for 6 days for soybean and 8 days for corn, then moved to room temperature $\left(22\right.$ to $\left.25^{\circ} \mathrm{C}\right)$ for another 2 days before disease ratings were made. Each isolate was considered as one treatment, and there were three replicate plates for each isolate.

The rating scales on corn and soybean were established based on preliminary experiments. On soybean, a preliminary study showed consistency among replicates in the symptoms of seed rot, root discol- oration, and root stunting. The symptoms on corn were seed rot, root discoloration, and root rot. Isolates consistently differed in their ability to cause corn seed rot, but not root rot. Therefore, the disease rating scale for soybean differed from that for corn. The rating scale for aggressiveness on soybean was: $0=$ seed germinated without visible infection (a seed was defined as germinated when the primary root length equaled the seed length); $1=$ germinated with light discoloration on roots; $2=$ germinated with short, severely discolored roots; $3=$ died after germination; $4=$ died

Table 1. Number of fields, number of isolates, sources of isolation, and methods used in pathogenicity tests of isolates of Pythium populations obtained from corn-soybean rotation fields ${ }^{\mathrm{a}}$

\begin{tabular}{lcccl}
\hline Population & Year & No. of isolates & No. of fields & Source of isolates \\
\hline 1 & 1994 & 24 & 4 & Soil \\
2 & 1993 & 41 & 19 & Soybean seedlings \\
3 & 1994 & 35 & 17 & Soybean seedlings \\
4 & 1995 & 33 & 15 & Soybean seedlings \\
5 & 1995 & 30 & 18 & Corn seedlings \\
$6^{\text {b }}$ & $1993-1995$ & 23 & 23 & Seedlings \\
\hline
\end{tabular}

a See text for details of each inoculation method for testing pathogenicity.

${ }^{\mathrm{b}}$ Isolates of this population are a mixture of Pythium ultimum isolates from populations 2 to 4 .
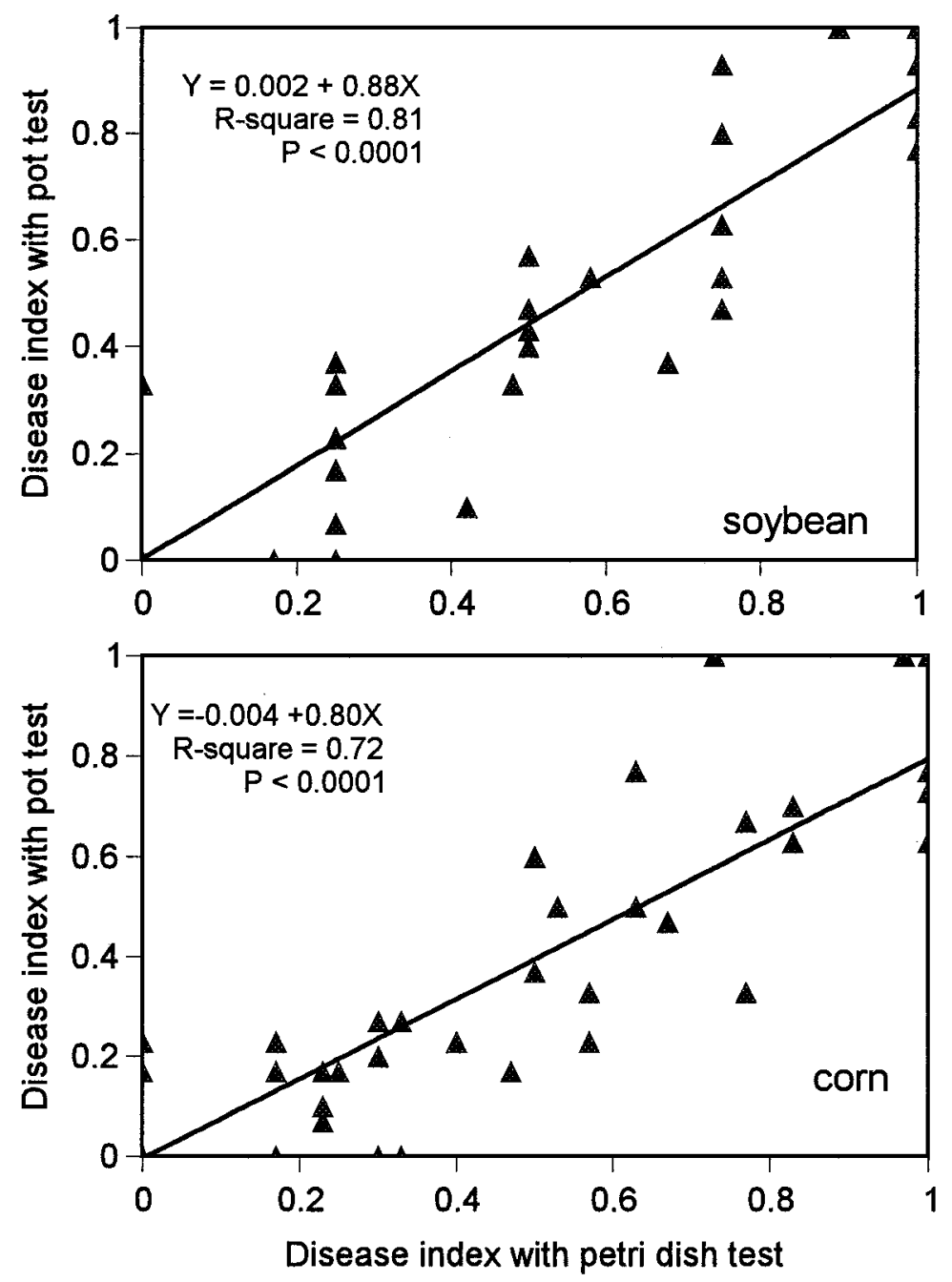

Fig. 1. Regression analyses between disease indices obtained with two testing methods: (i) inoculation in petri dishes containing water agar and (ii) inoculation by Pythium-infested soil in pots. Disease indices were compared for two hosts: soybean and corn. before germination. Measurement of agen an isolate on soybean was calculated as a disease index from the fol-

$$
Y=\sum_{i=1}^{3} x_{i} / 12
$$

where $Y$ is disease index (scale 0 to 1 ), $x_{i}$ is disease rating of the $i$ th replicate $(i=1$ to 12 equals the number of replicates ing for corn was based on the number of ungerminated seeds. The disease indices that measure aggressiveness of each isolate

.

西


on corn was expressed as the proportion of ungerminated seeds.

Pot test. Pythium isolates were transferred to potato dextrose agar (PDA) and incubated at room temperature (22 to $25^{\circ} \mathrm{C}$ ) for 7 days in the dark. The cultures were cut into small pieces $\left(<0.5 \mathrm{~cm}^{2}\right)$ and mixed with sterilized soil mix (40\% Canadian peat moss, $40 \%$ perlite, and $20 \%$ soil) at a ratio of one petri dish $(100 \times 15 \mathrm{~mm})$ per pot (500-ml plastic pots $13 \mathrm{~cm}$ deep). Three replicate pots were planted for each isolate, with 10 corn or soybean seeds per pot at a depth of $4 \mathrm{~cm}$. Controls were established by planting seeds in soil mix amended with plain PDA. Pots were incubated at $12^{\circ} \mathrm{C}$ for 7 days in the dark and then at $24^{\circ} \mathrm{C}$ for 4 days in growth chambers with a 10-h light period, after which the disease ratings were made. The results of a preliminary study showed that differences in ability to reduce corn and soybean seed emergence were significant among the Pythium isolates and consistent among replicates. Therefore, the disease index of an isolate, as determined by pot test method, was defined as the proportion of nonemerged seeds for both crops.

The pot test and the petri dish methods were compared, and their relationship was determined with regression analysis using the same set of isolates from soil, soybean seedlings, or corn seedlings. The determination coefficient of regression between the two methods was calculated, and its significance was tested with a $t$ test.

Analysis of data. Isolates were considered highly aggressive when their aggressiveness value was equal to or greater than 0.5 . To determine the relationship between pathogenicity to soybean and pathogenicity to corn for each Pythium population, the values for individual isolates of each experiment were plotted and examined on a two-dimensional graph, with $\mathrm{X}$ representing pathogenicity on soybean and Y representing pathogenicity on corn. The regression between aggressiveness on corn and on soybean was then calculated using the disease index on corn and on soybean.

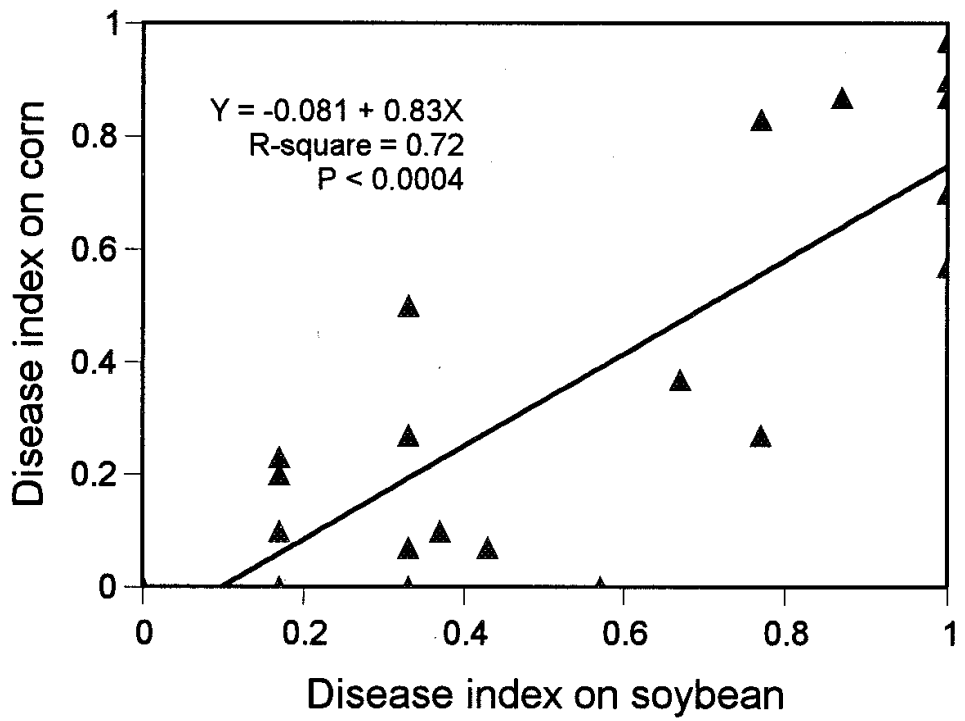

Fig. 2. Regression analysis between disease index on corn and on soybean for Pythium isolates from soil collected in four long-term corn-soybean rotation fields (population 1). Virulence tests were conducted by using the petri dish test for both corn and soybean. Disease index on corn was expressed as the proportion of ungerminated seeds.

Table 2. Number of isolates per group with different levels of aggressiveness on corn or soybean in the Pythium populations collected from 1993 to 1995 from corn-soybean rotation fields

\begin{tabular}{|c|c|c|c|c|c|}
\hline \multirow[b]{2}{*}{ Population $^{\text {b }}$} & \multicolumn{5}{|c|}{ Groups with different level of aggressiveness on corn-soybean $^{\text {a }}$} \\
\hline & No/no ${ }^{c}$ & Low/low $^{\text {d }}$ & Low/high & High/low & High/high \\
\hline 1 & 4 & 9 & 3 & 1 & 7 \\
\hline 2 & 0 & 8 & 4 & 4 & 25 \\
\hline 3 & 0 & 6 & 12 & 0 & 17 \\
\hline 4 & 0 & 6 & 5 & 1 & 21 \\
\hline 5 & 0 & 12 & 4 & 1 & 13 \\
\hline
\end{tabular}

a For each group, level above "/" is for corn and below is for soybean.

${ }^{\mathrm{b}}$ Isolates of population 1 were from soil, populations 2 to 4 from diseased soybean seedlings, and population 5 from corn seedlings.

${ }^{\mathrm{c}}$ Isolates of this group were not pathogenic to either soybean or corn.

${ }^{\mathrm{d}}$ Aggressiveness on corn was proportion of ungerminated seeds in petri dish test or proportion of nonemerged seeds in pot test. Low means disease rating was less than 0.5 , and high means rating was greater than or equal to 0.5 . Low aggressiveness on soybean means disease index was less than 0.5 , and high means index was greater than or equal to 0.5 .
Significance of the regression was tested for each population by SAS REG (SAS Institute, Cary, NC). A separate analysis also was made for $P$. ultimum to evaluate the relationship between aggressiveness on corn and on soybean within this species.

\section{RESULTS}

Isolation and symptoms. Over a 3-year period, 163 Pythium isolates were obtained from soil and diseased plants in 73 fields (Table 1). In the petri dish test, uninoculated soybean and corn seeds germinated and grew normally with no observed lesions or discoloration. The most severe symptoms on inoculated soybean seeds were complete rotting and colonization of ungerminated seeds. Some isolates rotted the seeds shortly after they germinated. Some isolates did not cause seed rot, but instead caused discolored roots. In some cases, the discolored roots were shorter than those of the control. On corn, pathogenic isolates caused seed rot, root discoloration, or root rot. In the pot test with infested soil, pathogenic isolates killed soybean and corn seeds before or after germination. Isolates varied in ability to reduce corn or soybean emergence. Some plants that emerged in the pots had yellow and necrotic lesions on roots and/or the bases of the hypocotyl. Corn and soybean seeds placed in noninfested soil emerged and did not develop necrotic lesions.

Comparison of petri dish test and pot test results. Linear regression revealed that there was a strong positive relationship between disease index values obtained by the petri dish and pot test methods $(P<$ 0.001) (Fig. 1). The coefficients of determination were 0.81 on soybean and 0.74 on corn. Interestingly, the two regression slopes, $b=0.80$ for corn and 0.88 for soybean, were not significantly different $(P>$ 0.05).

Pathogenicity and disease index of the isolates from soil. Seventeen of 24 isolates from soil $(71 \%)$ exhibited various levels of aggressiveness on both corn and soybean (Fig. 2). Four isolates were not pathogenic to either crop (Table 2). Seven isolates $(29 \%)$ were highly aggressive, with disease index greater than 0.5 on both hosts. There were three isolates $(18 \%)$ whose disease index values were high to soybean but low to corn. Nine isolates had low disease index values on both crops.

Pathogenicity and disease index of isolates from soybean seedlings. More than $85 \%$ of the isolates from diseased soybean seedlings (populations 2, 3, and 4) infected both corn and soybean (Fig. 3). The proportion of isolates that had different values of disease index on corn and soybean varied among the three populations (Table 2), from 49 to $64 \%$ of the isolates having a disease index equal to or greater than 0.5 on both corn and soybean. Seventeen to $20 \%$ of the isolates were high in aggressiveness on both corn and soy- 
bean. For all populations, few isolates that were highly aggressive on corn had low values of disease index on soybean.

Pathogenicity and disease index of isolates from corn seedlings. Twentyseven out of 30 isolates $(87 \%)$ from diseased corn seedlings (population 5) reduced emergence of both corn and soybean, and 13 of those isolates (43\%) were highly aggressive on both corn and soybean (Fig 4, Table 2). Four isolates were highly aggressive on soybean but weakly aggressive on corn, and one was highly aggressive on corn but weakly aggressive on soybean. Twelve isolates (40\%) exhibited a low level of aggressiveness on both corn and soybean. Seventeen isolates $(63 \%)$ were highly aggressive on soybean, $14(47 \%)$ were highly aggressive on corn.

Pathogenicity within $P$. ultimum. Twenty-three isolates of $P$. ultimum (population 6) from diseased soybean seedlings were assessed for aggressiveness using the pot test. Seventy percent of the $P$. ultimum isolates were highly aggressive on both corn and soybean (Fig. 5). The disease index on soybean varied from 0.3 to 1 with a mean of 0.86 and a standard deviation of 0.23 . On corn, the disease index ranged from 0.3 to 1 with a mean of 0.59 and a standard deviation of 0.31 , which was not significantly different from the mean of soybean. Three isolates (13\%) were highly aggressive on soybean but weakly aggressive on corn.

Regression analysis. Variation in disease index on corn or on soybean varied among the Pythium isolates, but the relationships between index values on corn and on soybean were highly significant $(P<$ 0.001) for all Pythium populations (Figs. 2 to 5). The values of regression coefficients or slopes were less than that of $y=x$ (slope $=1.0)$ in all experiments, suggesting a higher measurement of disease index values to soybean than to corn with the test methods we used.

\section{DISCUSSION}

Our 3-year study showed that populations of the Pythium spp. collected from corn-soybean rotation fields contain high frequencies of isolates pathogenic to both crops, and that the disease index on soybean is significantly correlated with the disease index on corn. Relationships between aggressiveness on corn and on soybean (as measured by disease index) were consistent for all tested Pythium populations, regardless of whether a population was obtained from soil, soybean seedlings, or corn seedlings. Such a relationship also was found for a population of P. ultimum from corn-soybean rotation fields.

The methods employed to test pathogenicity in our study have been used previously to study Pythium diseases of different crops $(5,9,10,25)$. The petri dish method consistently differentiated levels of aggressiveness among Pythium isolates in previous studies $(5,25)$. Thomson et al. (25) used the petri dish and infested soil methods to compare $P$. debaryanum and $P$. ultimum for their potential in reduction of soybean emergence and found that the petri dish tests were more discriminating for detecting differences in aggressiveness than tests in infested soil. They also tested the effects of different temperatures on disease index, and the petri-dish tests yielded greater differences among the tem-
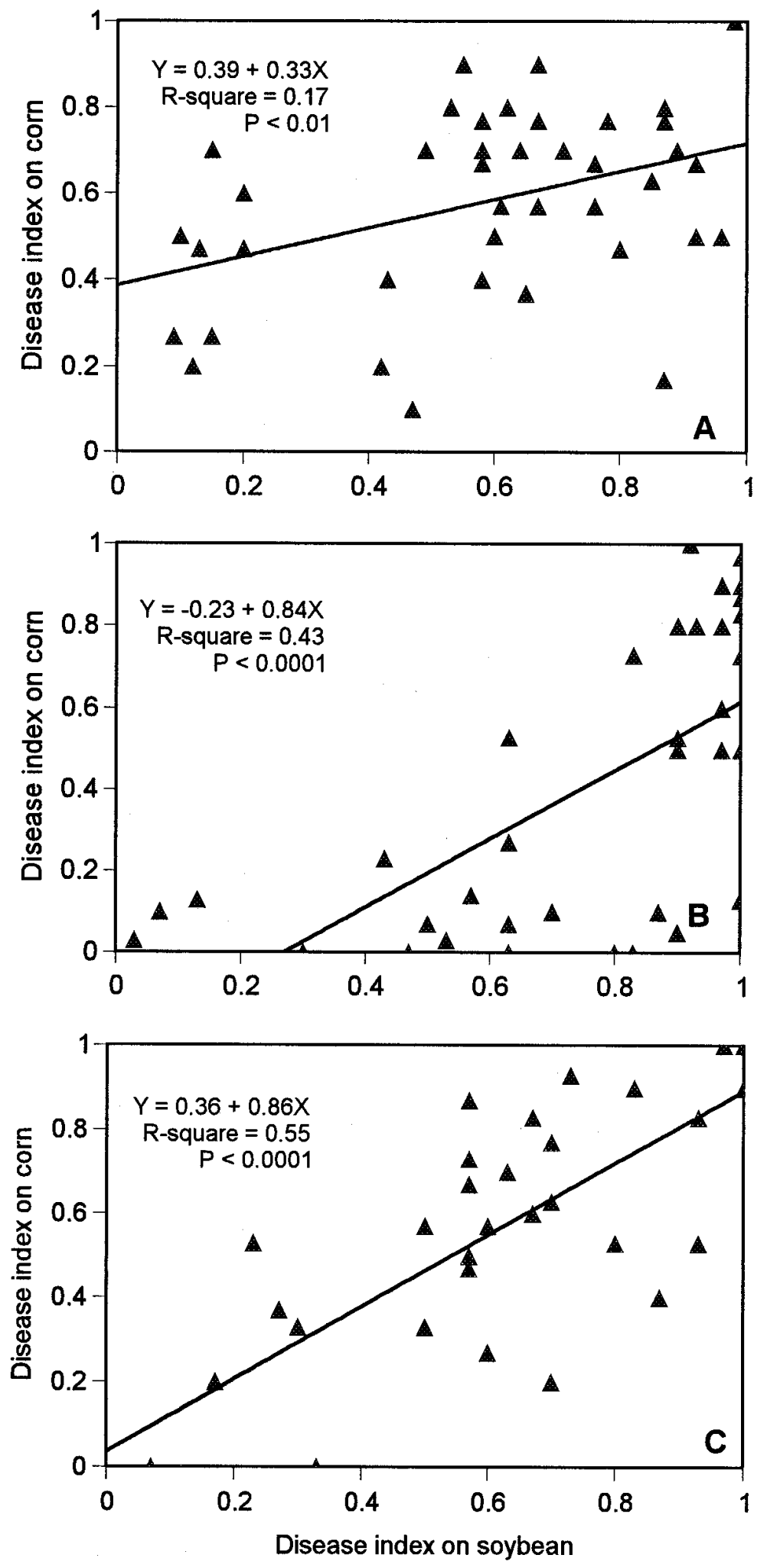

Fig. 3. Regression analysis between disease index on corn and on soybean for Pythium isolates from diseased soybean seedlings collected from 19, 17, and 15 corn-soybean rotation fields during 1993, 1994, and 1995 (populations 2, 3, and 4; see Table 1), respectively. Population 2 was tested using the petri dish test (A). Populations 3 (B) and 4 (C) were conducted using the pot test. 
perature treatments than did the infested soil test. The petri dish test also was used to test resistance of corn to Pythium $(5,9)$. The results of our study showed significant two methods for disease index on corn or soybean (Fig. 1), indicating repeatability between the two methods.

Because Pythium spp. usually cause seedling diseases (pre- and postemergence damping-off) under a low-temperature environment, low incubation temperatures $\left(10\right.$ to $\left.12^{\circ} \mathrm{C}\right)$ were used in this study. In previous studies, pretreatment of 10 to $15^{\circ} \mathrm{C}$ was used to induce the development of the disease $(2,5,10,25)$. Low temperatures may alter physiological processes of coefficients of determination between the

seed germination, and seedling growth may be detrimentally affected (25). Pythium spp., however, can grow normally at low temperatures (27). These factors together may make younger seedlings and germinating seeds more susceptible to Pythium spp.

Different patterns in distribution of disease indices were found among the $P y$ thium populations (Figs. 2 to 4, Table 2). For instance, the populations from diseased soybean seedlings (populations 2-4, Fig 3) had more isolates that were highly aggressive than the population of isolates from soil (population 1, Fig. 2). It is easy to understand that a pathogen population from diseased seedlings would have a

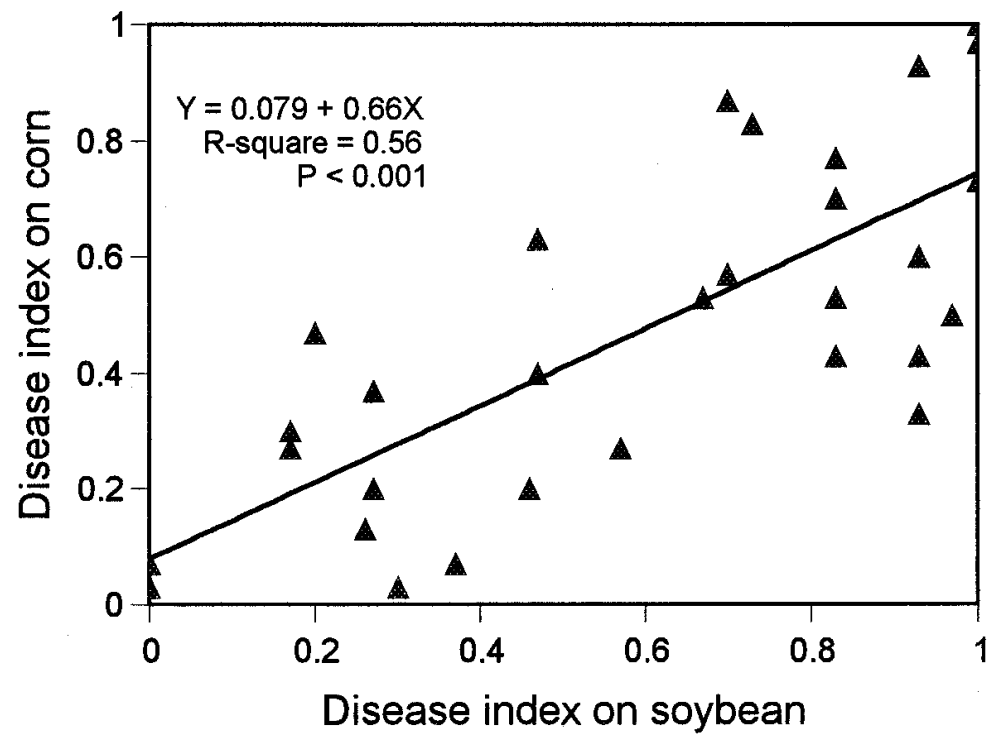

Fig. 4. Regression analysis between disease index on corn and on soybean for Pythium isolates obtained from diseased corn seedlings from 18 corn-soybean rotation fields during 1995. Tests were conducted using the pot test (see text). Disease index on soybean and corn was expressed as the proportion of nonemerged seeds.

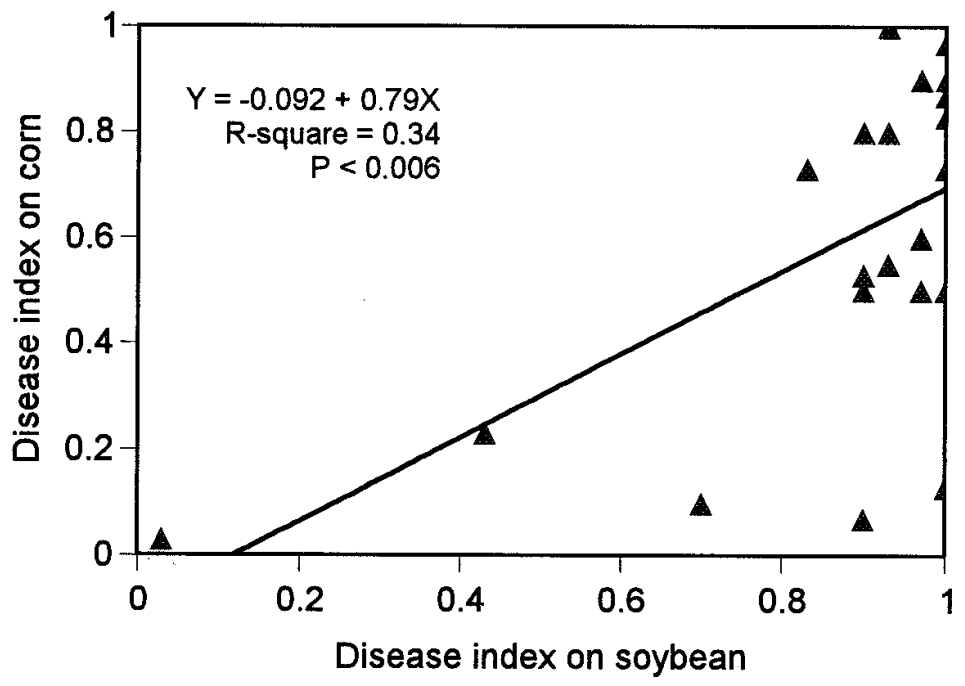

Fig. 5. Regression analysis between disease index on corn and on soybean for Pythium ultimum isolated from diseased soybean seedlings from corn-soybean rotation fields in 1993 to 1995 . The tests were conducted using the pot test. Disease index on soybean and corn was expressed as the proportion of nonemerged seeds. greater frequency of highly aggressive isolates than a population from soil. When analogous sources of Pythium isolates were tested by the same method, the patterns were similar; for example, Pythium populations from either diseased soybean or corn seedlings collected from adjacent fields had similar disease indices. Variation among experiments could also be due to cultivar effects, as the case of population 3 and population 4 .

Our data showed that the isolates in each Pythium population had a great variation in pathogenicity on corn, soybean, or both. The variation in pathogenicity of Pythium populations may be from two sources: differences in aggressiveness among $P y$ thium species and/or differences in aggressiveness among isolates within a species. McCarter and Littrell (16) tested pathogenicity of 14 isolates of $P$. aphanidermatum and $P$. myriotylum on 12 crops. Pythium isolates were collected from various sources: plant (such as tomato, Citrus sp., Chrysanthemum sp., rye, peanut, and bean), soil, and some unknown sources. They found that the two species caused different levels of disease on a certain crop, and the aggressiveness of the two species was not always consistent among crops. For instance, $P$. aphanidermatum was more aggressive on cucumber than on bean compared with $P$. myriotylum. Isolates within species had different disease indices on the same crops. Studies $(17,20)$ on forest soil converted to agricultural lands showed that populations of pathogenic Pythium spp. such as P. ultimum, which are pathogenic to corn and soybean $(7,21,22)$, increased rapidly. Zhang et al. (28) compared relative abundance of $P y$ thium species among three long-term cropping systems: continuous corn, continuous soybean, and corn-soybean rotation. Four Pythium species were isolated most frequently: P. ultimum, $P$. torulosum, P. paroecandrum, and $P$. spinosum. They reported that the incidences of Pythium isolates recovered from corn-soybean and soybean-soybean fields were significantly greater than that from corn-corn rotation fields. P. torulosum and P. ultimum were isolated in higher frequencies compared with other species. In this study, species identifications of all individual isolates were not completed. Further study to correlate relative abundance of individual species to disease levels may provide further insights on how long-term corn-soybean rotation affects Pythium root rot.

The long-term use of a single cropping system may also result in variation in pathogenicity of Pythium isolates within species. Previous studies $(1,12,16)$ showed variation in pathogenicity within Pythium species and indications of variation in pathogenicity as a result of long-term use of a single cropping system $(12,19)$. Hoppe and Middleton (12) reported that isolates of $P$. ultimum differed in their ability to 
cause preemergence death of corn. Variation among $P$. ultimum isolates in causing preemergence damping-off of soybean was reported by Brown and Kennedy (1). Similarly, we found differences in aggressiveness on corn or soybean among the isolates of $P$. ultimum tested (Fig. 5).

The presence of highly and lowly aggressive isolates of certain pathogenic species in a pathosystem may indicate selection pressures a cropping system places on the pathogen (11). The variation in aggressiveness in Pythium populations may be a result of adaptation of the $P y$ thium populations to rotation crops. Considering the variation in aggressiveness of Pythium populations, it would be interesting to determine whether long-term use of corn-soybean rotation could result in $P y$ thium populations that are more aggressive on both crops.

\section{ACKNOWLEDGMENTS}

We thank S. A. A. Rizvi for assistance in isolation, W. Chen for assistance in identification of Pythium species, and J. Hoy and C. Xiao for critical reviews. The paper is a portion of the M.S. thesis of the first author. This project was supported in part by the Hatch Act and State of Iowa funds.

\section{LITERATURE CITED}

1. Brown, G. E., and Kennedy, B. W. 1965. Pythium pre-emergence damping-off of soybean in Minnesota. Plant Dis. Rep. 49:646.

2. Crawford, R. P. 1982. Comparison of Pythium ultimum resistance and cold tolerance in maize. M.S. thesis. Iowa State University, Ames.

3. Doupnik, B., Jr. 1993. Soybean production and disease loss estimates for North Central United States from 1989 to 1991. Plant Dis. 77:1170-1171.

4. Fehr, W. R., Caviness, C. E., Burmood, D. T., and Pennington, J. S. 1971. Stage of development descriptions for soybeans, Glycine $\max$ (L.) Merr. Crop Sci. 11:929-931.

5. Foley, D. C. 1980. Resistance to Pythium debaryanum in Zea mays seedlings. Proc. Ia. Acad. Sci. 87:134-138.

6. Gay, J. D. 1969. Effects of temperature on snap bean damping-off caused by three isolates of Pythium myriotylum. Plant Dis. Rep. 53:707-709.

7. Griffin, G. J. 1990. Importance of Pythium ultimum in a disease syndrome of cv. Essex soybean. Can. J. Plant Pathol. 12:135-140.

8. Hendrix, F. F., Jr., and Campbell, W. A. 1973. Pythiums as plant pathogens. Annu. Rev. Phytopathol. 11:77-98.

9. Hooker, A. L. 1951. The corn embryo as a factor in resistance in Pythium during germination. Phytopathology 41:17.

10. Hooker, A. L. 1953. Relative pathogenicity of Pythium species attacking seedling corn. Proc. Ia. Acad. Sci. 60:163-166.

11. Hooker, A. L. 1953. Severity of corn seedling disease in Iowa soils. Proc. Ia. Acad. Sci. 60:158-162.

12. Hoppe, P. E., and Middleton, J. T. 1950. Pathogenicity and occurrence in Wisconsin soils of Pythium species which cause seedling disease in corn. (Abstr.) Phytopathology 40:13.

13. Iowa State University Cooperative Extension Service. 1993. How A Corn Plant Develops. Spec. Rep. 48. Ia. St. Univ. Coop. Ext. Serv., Ames.

14. Johann, H., and Holbert, J. R. 1928. A Pythium seedling blight and root rot of dent corn. J. Agric. Res. 37:433-464.

15. Martin, F. N. 1992. Pythium. Pages 39-49 in: Methods for Research on Soilborne Phytopathogenic Fungi. T. B. Singleton, T. B. Athow, J. D. Mihail, and C. M. Rush, eds. American Phytopathological Society, St. Paul, MN.

16. McCarter, S. M., and Littrell, R. H. 1970. Comparative pathogenicity of Pythium aphanidermatum and $P$. myriotylum to twelve plant species and intraspecific variation in virulence. Phytopathology 60:264-268.
17. Miller, J. H., Giddens, J. E., and Foster, A. A 1975. A survey of the fungi of forest and cultivated soils of Georgia. Mycologia XLIX:779-807.

18. Pankhurst, C. E., McDonald, H. J., and Hawke, B. G. 1995. Influence of tillage and crop rotation on the epidemiology of Pythium infections of wheat in a red-brown earth of south Australia. Soil Biol. Biochem. 27:10651073.

19. Phillips, A. J. L. 1991. Variation in virulence to dry beans, soybeans and maize among isolates of Rhizoctonia solani from beans. Assoc. Appl. Biol. 118:9-17.

20. Reeleder, R. D., and Hagedorn, D. J. 1981. Pythium populations in Wisconsin bean fields. Can. J. Plant Pathol. 3:90-93.

21. Rizvi, S. A. A., and Yang, X. B. 1996. Fungi associated with soybean seedling disease in Iowa. Plant Dis. 80:57-60.

22. Schmitthenner, A. F. 1962. Effect of crop rotation on Pythium ultimum and other Pythium species in the soil. (Abstr.) Phytopathology 52:27.

23. Semeniuk, G. 1948. Root rot in your corn. Ia Farm Sci. 3(2):6-7.

24. Southern, J. W., Schenck, N. C., and Mitchell, D. J. 1976. Comparative pathogenicity of Pythium myriotylum and $P$. irregulare to the soybean cultivar Bragg. Phytopathology 66:1380-1385.

25. Thomson, T. B., Athow, K. L., and Laviollete, F. A. 1971. The effect of temperature on the pathogenicity of Pythium aphanidermatum, $P$. debaryanum, and $P$. ultimum on soybean. Phytopathology 61:933-935.

26. Tsao, P. H., and Ocana, G. 1969. Selective isolation of species of Phytophthora from natural soils on an improved antibiotic medium. Nature 223:636-638.

27. Van der Plaats-Niterink, A. J. 1981. Monograph of the genus Pythium. Stud. Mycol. 21:1-239.

28. Zhang, B. Q., Chen, W. D., and Yang, X. B. 1998. Occurrence and relative abundance of Pythium species in long-term corn and soybean monoculture and corn/soybean rotation fields. Mycol. Res. 102:1450-1452. 